\title{
Factors Associated with Moderate to Severe Pain after Laparoscopic Surgery
}

\author{
Thitikan Kunapaisal, M.D. ${ }^{1}$, Ngamjit Pattaravit, M.D. ${ }^{1}$, Paramee Thongsuksai, M.D. ${ }^{2}$ \\ 'Department of Anesthesiology, Faculty of Medicine, Prince of Songkla University, Hat Yai, Songkhla 90110, Thailand. \\ 2Department of Pathology, Faculty of Medicine, Prince of Songkla University, Hat Yai, Songkhla 90110, Thailand. \\ Received 27 June 2020 • Revised 9 August 2020 • Accepted 22 October 2020 • Published online 26 March 2021
}

\begin{abstract}
:
Objective: The aim of this study was to describe associated factors of patients with moderate to severe pain after laparoscopic abdominal surgery in Post Anesthetic Care Unit.
\end{abstract}

Material and Methods: This retrospective study included patients who underwent laparoscopic abdominal surgeries (bariatric, colorectal, gynecological, urological, and upper gastrointestinal surgery) between February and July 2019. Demographic data were retrieved from the anesthetic records. Pain score was evaluated by self- rating using verbal numerical rating scale (0-10). Logistic regression was used to obtain independent risk factors of moderate to severe (score 4-10) pain against no or mild pain.

Results: Two-hundred and ten patients were included. The incidence of moderate (score 4-6) to severe pain (score 7-10) was $50.0 \%$. Those who suffered from moderate to severe pain required higher consumption of analgesic drugs in recovery room than the other groups, however durations of hospitalization were not different between the two groups $(p-v a l u e=0.329)$. This was because the highest intensity of pain was in the first postoperative day. A multivariate logistic regression analysis revealed that abdominal pressure more than $12 \mathrm{mmHg}$ (odd ratio $(O R)=1.84,95 \%$ confidence interval (Cl) 0.8-4.22, p-value=0.153), and operation time more than 3 hours (OR 1.49, 95\% Cl 0.86-2.61, p-value=0.158) were independent risk factors of moderate to severe pain after laparoscopic procedure

Conclusion: High intra-abdominal pressure $(\geq 12 \mathrm{mmHg}$ ) and prolonged operation time ( $>3$ hours) are the independent risk factors of moderate and severe pain in laparoscopic surgery.

Keywords: factors, moderate to severe pain, laparoscopic surgery

Contact: Thitikan Kunapaisal, M.D.

Department of Anesthesiology, Faculty of Medicine,

Prince of Songkla University, Hat Yai, Songkhla 90110, Thailand.

E-mail: thitikan070@gmail.com

This is an open access article under the CC BY-NC-ND license

(http://www.jhsmr.org/index.php/jhsmr/about/editorialPolicies\#openAccessPolicy).

J Health Sci Med Res 2021;39(5):365-372 doi: 10.31584 /jhsmr.2021792 www.jhsmr.org 


\section{Introduction}

Postoperative pain is a common post-surgical problem, which prolongs recovery and delays hospital discharge. ${ }^{1}$ Consequently, surgeons have been persuaded to apply surgical techniques with minimal invasiveness in order to reduce postoperative pain, one of which is laparoscopic surgery. However, moderate to severe pain are also reported after laparoscopic surgical procedures, and a previous study reported that laparoscopic surgery had higher analgesic requirement than laparotomy surgery. ${ }^{2}$ The frequency of moderate to severe pain has been demonstrated as high as 50.0-60.0\%., Therefore the knowledge regarding factors associated moderate to severe pain in laparoscopic surgeries is important for controlling pain.

Postoperative pain is likely related to multifactorial factors including patient factors, surgical factors, and anesthetic factors. Previous literature has reported and focused only on patient factors. These studies reported young age ${ }^{4}$, pre-existing pain ${ }^{5}$, female $e^{6,7}$, and obese patients which are patient factors associated pain. However few studies documented surgical factors including duration of surgery, port site and intra-abdominal pressure ${ }^{8,9}$, which would be correlated with pain after laparoscopic procedures. Moreover, anesthetic factors such as local infiltration

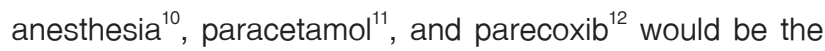
prophylactic factors to reduce pain.

Regarding the aforementioned information, there is a lack of information about surgical and anesthetic factors in abdominal surgery. To fulfil this knowledge gap, the aim of this study was to describe associated factors and outcomes of patients with moderate to severe pain after any type of laparoscopic surgery.

\section{Material and Methods}

This was a retrospective cross-sectional study. The research retrieved the records of 210 patients which underwent laparoscopic surgery (bariatric, colorectal (laparoscopic low anterior resection), gynecological, urological, and upper GI surgery (laparoscopic cholecystectomy, laparoscopic gastrectomy) in Songklanagarind Hospital, a tertiary hospital in southern Thailand between February and July 2019. The inclusion criteria were age $\geq 18$ years old, laparoscopic surgery, and American Society of Anesthesiologists (ASA) classification I-III. Exclusion criteria were converting to explore laparotomy, and emergency case. All data (demographic data, ASA classification, type of surgery, duration of surgery, and pain score at recovery room) were extracted from anesthetic records in the Anesthesiology department. Consequently, we reviewed and obtained port site operation, abdominal pressure from operative notes, duration of hospitalization, and opioid consumption in the 24 hour post-operative period from electronic medical records of this hospital. The primary outcome of this study was pain evaluated by the patient based on verbal numerical rating scale (0-10) at Post Anesthetic Care Unit after laparoscopic surgery. The scores were categorized into no pain (0), mild pain (1-3), moderate pain (4-6), and severe pain (7-10). Then patients were divided into two groups, no/mild pain and moderate to severe pain. The secondary outcomes were opioid consumption in the recovery room, and 24 hour postoperative period, and duration of hospitalization among groups.

The sample size was calculated based on the difference in a previously reported proportion of moderate/ severe pain in obesity patients [proportion $(p)=0.43$ ] and the proportion of mild pain in obesity patients $(p=0.23){ }^{7}$ Using a two-sided test with a 95\% confidence interval $(\mathrm{Cl})$ 
and type II error of 0.2 , the calculated sample size was 96 patients/group. The number was increased by $10.0 \%$ drop out to compensate for excluded cases.

Statistical analysis was performed using program R. Categorical variables such as gender, body mass index (BMI), ASA classification, type of laparoscopic surgery, type of intraoperative opioid, paracetamol and parecoxib use were demonstrated as percentage and proportion. Continuous variables such as weight, height, duration of hospitalization, and opioid consumption were presented as mean and standard deviation or median and interquartile range. The parameters were compared between moderate/ severe pain and no/mild pain group by Student t-test or Wilcoxon Rank Sum test as appropriate. Categorical variables were analyzed using chi-squared test or Fisher' Exact test as appropriate. Variables with $p$-value $<0.200$ were included in multivariate logistic regression model. A p-value less than 0.050 was considered statistically significant.

\section{Results}

A total of 212 patients were assessed for study eligibility, 210 patients were retrieved in this study. Two patients were excluded from this study due to converting to explore laparotomy. Hence 105 patients of each group were available for analysis (Figure 1).

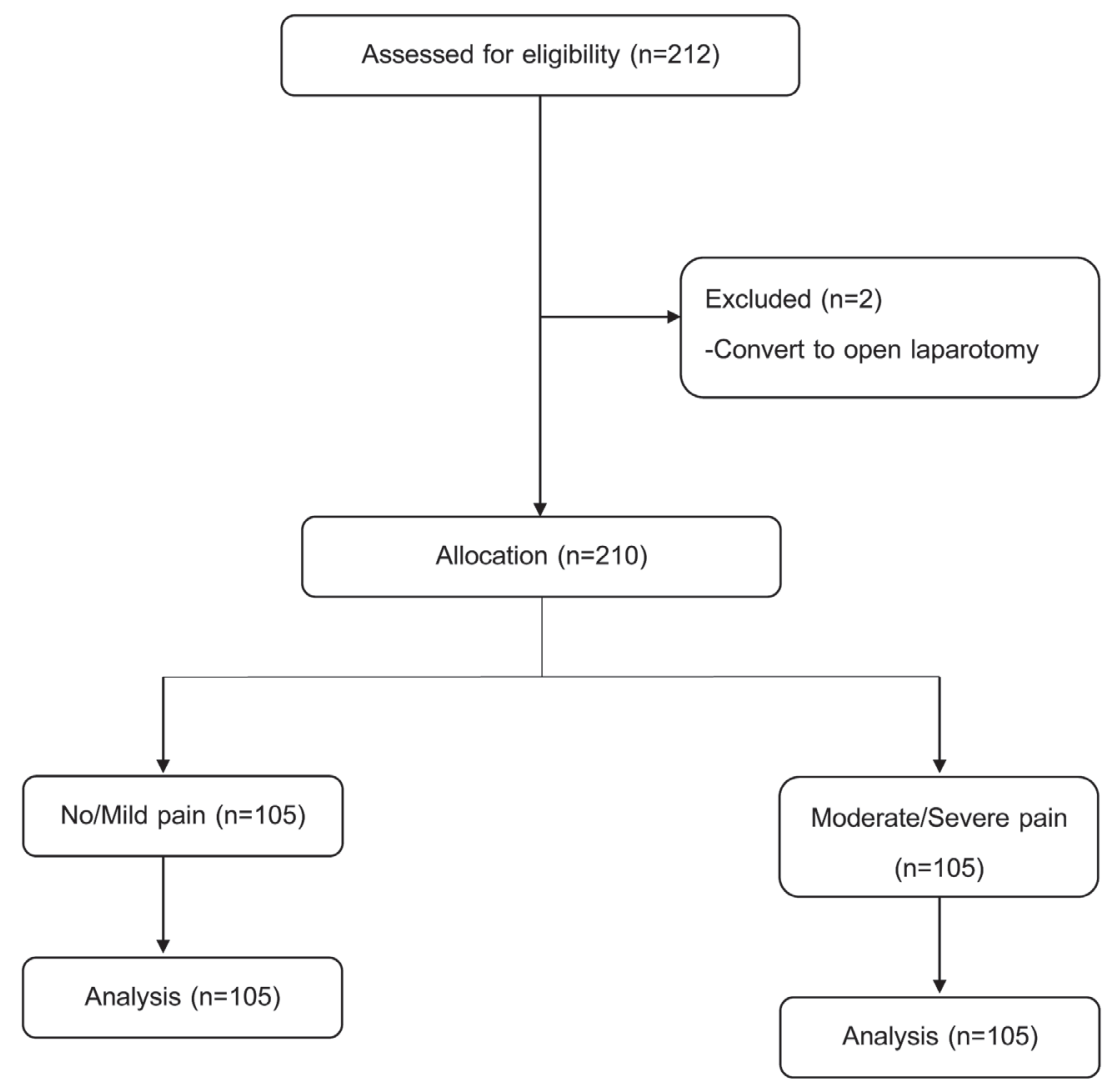

Figure 1 Consort flow diagram 
Table 1 Characteristic data of patients in laparoscopic surgery

\begin{tabular}{|c|c|c|c|}
\hline Variables & $\begin{array}{l}\text { No/mild pain } \\
(n=105)\end{array}$ & $\begin{array}{l}\text { Moderate/severe pain } \\
(n=105)\end{array}$ & p-value \\
\hline \multicolumn{4}{|l|}{ Age (years) } \\
\hline$\leq 40$ & $32(47.8)$ & $35(52.2)$ & \multirow[t]{2}{*}{0.767} \\
\hline$>40$ & $73(51.0)$ & $70(49.0)$ & \\
\hline Weight (kg), median (IQR) & $60(51.0,70.0)$ & $65(57.0,87.0)$ & 0.005 \\
\hline Height (cm), mean (S.D.) & $159.3(8.4)$ & $161.3(8.0)$ & 0.076 \\
\hline \multicolumn{4}{|l|}{$\mathrm{BMI}\left(\mathrm{kg} / \mathrm{m}^{2}\right)$} \\
\hline$<35$ & $92(53.8)$ & $79(46.2)$ & \multirow[t]{2}{*}{0.033} \\
\hline$\geq 35$ & $13(33.3)$ & $26(66.7)$ & \\
\hline \multicolumn{4}{|l|}{ Sex } \\
\hline Male & $35(51.5)$ & $33(48.5)$ & \multirow[t]{2}{*}{0.883} \\
\hline Female & $70(49.3)$ & $72(50.7)$ & \\
\hline \multicolumn{4}{|l|}{ ASA classification } \\
\hline I & $8(57.1)$ & $6(42.9)$ & \multirow[t]{3}{*}{0.679} \\
\hline II & $70(51.1)$ & 67 (48.9) & \\
\hline III & $27(45.8)$ & $32(54.2)$ & \\
\hline \multicolumn{4}{|l|}{ Technic of anesthesia } \\
\hline GA alone & $104(49.8)$ & $105(50.2)$ & \multirow[t]{2}{*}{1.000} \\
\hline GA combine RA & $1(100.0)$ & $0(0.0)$ & \\
\hline \multicolumn{4}{|l|}{ Type of surgery } \\
\hline Bariatric surgery & $9(29.0)$ & $22(71.0)$ & \multirow[t]{5}{*}{0.124} \\
\hline Gynecological surgery & $38(55.1)$ & $31(44.9)$ & \\
\hline Upper Gl surgery & $28(54.9)$ & $23(45.1)$ & \\
\hline Colorectal surgery & $26(53.1)$ & $23(46.9)$ & \\
\hline Urological surgery & $4(40.0)$ & $6(60.0)$ & \\
\hline \multicolumn{4}{|l|}{ Abdominal pressure $(\mathrm{mmHg})$} \\
\hline $\begin{array}{l}\text { Pressure }<12 \mathrm{mmHg} \\
(P \text { mean }=10 \mathrm{mmHg})\end{array}$ & $17(63.0)$ & $10(37.0)$ & \multirow[t]{2}{*}{0.216} \\
\hline $\begin{array}{l}\text { Pressure } \geq 12 \mathrm{mmHg} \\
(\mathrm{P} \text { mean }=15 \mathrm{mmHg})\end{array}$ & $88(48.1)$ & $95(51.9)$ & \\
\hline \multicolumn{4}{|l|}{ Duration of surgery (mins) } \\
\hline$\leq 180$ & $69(53.9)$ & $59(46.1)$ & \multirow[t]{2}{*}{0.203} \\
\hline$>180$ & $36(43.9)$ & $46(56.1)$ & \\
\hline \multicolumn{4}{|l|}{ Port } \\
\hline Single port & $8(53.3)$ & $7(46.7)$ & \multirow[t]{2}{*}{1.000} \\
\hline Multiple ports & $97(49.7)$ & $98(50.3)$ & \\
\hline \multicolumn{4}{|l|}{ Local infiltration } \\
\hline Yes & $97(50.8)$ & $94(49.2)$ & \multirow[t]{2}{*}{0.630} \\
\hline No & $8(42.1)$ & $11(57.9)$ & \\
\hline \multicolumn{4}{|c|}{ Types Opioid intraoperative use } \\
\hline Fentanyl & $80(49.7)$ & $81(50.3)$ & \multirow[t]{2}{*}{0.062} \\
\hline Morphine & $25(51.0)$ & $24(49.0)$ & \\
\hline \multicolumn{4}{|l|}{ Paracetamol IV intraoperative } \\
\hline Yes & $14(48.3)$ & $15(51.7)$ & \multirow[t]{2}{*}{1.000} \\
\hline No & $91(50.3)$ & $90(49.7)$ & \\
\hline NSAIDs IV intraoperative & & & \\
\hline Yes & $23(46.0)$ & $27(54.0)$ & 0.627 \\
\hline No & $82(51.2)$ & $78(48.8)$ & \\
\hline
\end{tabular}

Data are presented as number (\%), unless indicated otherwise.

$\mathrm{kg}=\mathrm{kilogram}, \mathrm{IQR}=$ interquartile range, $\mathrm{cm}=$ centimeter, S.D.=standard deviation, $\mathrm{BMl}=$ body mass index, $\mathrm{ASA}=\mathrm{American}$ Society of Anesthesiologists, $\mathrm{GA}=$ general anesthesia, $\mathrm{RA}=$ regional anesthesia, $\mathrm{Gl}=$ gastrointestinal, $\mathrm{P}=$ pressure, $\mathrm{mm}=\mathrm{millimeter}, \mathrm{Hg}=$ mercury, min=minute, NSAIDs=non-steroidal anti-inflammatory drugs, IV=intravenous 
Table 1 demonstrated no statistically significant differences in demographic data such as age, sex, ASA physical status, technique of anesthesia, and type of laparoscopic surgery among groups. Nonetheless moderate to severe pain group had a number of obese patients $(\mathrm{BMI} \geq 35)$, more significantly than other groups (average $\mathrm{BMI}=25 \mathrm{~kg} / \mathrm{m}^{2}$, and $23.7 \mathrm{~kg} / \mathrm{m}^{2}$, respectively $(p-$ value $=0.036)$.

Table 2 displayed fentanyl, and morphine consumption in recovery room, and morphine consumption in 24 hours were found higher in moderate to severe pain group than other groups, p-value $<0.001$. In addition, paracetamol and non-steroidal anti-inflammatory drugs (NSAIDs) consumptions were significantly higher in moderate/severe pain group than other groups ( $p-$ value=
0.029). On the other hand, durations of hospitalization were not different between the two groups.

Table 3 displays odds ratios of various variables associated with moderate to severe pain. The odds ratios from univariate analysis and logistic regression were interestingly different for $\mathrm{BMI}$, intra-abdominal pressure, and duration of surgery. Significant odds ratio of BMI (OR 2.33, 96 95\% Cl 1.12-4.84, p-value=0.023) became nonsignificant (OR 1.97, 95\% Cl 0.9-4.31, p-value=0.085). In contrast, nonsignificant intra-abdominal pressure (OR $1.84,95 \% \mathrm{Cl} 0.8-4.22, \mathrm{p}$-value=0.153), and operation time (OR 1.49, 95\% Cl 0.86-2.61, p-value=0.158) changed to be significant. Opioid use was consistently significant in univariate and multi-variate analysis.

Table 2 Analgesic use during post anesthetic care unit and postoperative period

\begin{tabular}{|c|c|c|c|}
\hline Variables & $\begin{array}{l}\text { No/mild pain } \\
(n=105)\end{array}$ & $\begin{array}{l}\text { Moderate/severe pain } \\
(n=105)\end{array}$ & p-value \\
\hline Fentanyl consumption in RR (mcg), median (IQR) & $0(0,0)$ & $25(0,50)$ & $<0.001$ \\
\hline Morphine consumption in RR (mg), median (IQR) & $0(0,0)$ & $0(0,2)$ & $<0.001$ \\
\hline \multicolumn{4}{|l|}{ Paracetamol IV in RR } \\
\hline Yes & $0(0.0)$ & $6(100.0)$ & 0.029 \\
\hline No & $105(51.5)$ & $99(48.5)$ & \\
\hline \multicolumn{4}{|l|}{ NSAIDs IV in RR } \\
\hline Yes & $0(0.0)$ & $6(100.0)$ & 0.029 \\
\hline No & $105(51.5)$ & $99(48.5)$ & \\
\hline Fentanyl consumption 24 hrs (mcg), median (IQR) & $0(0,30)$ & $0(0,0)$ & 0.305 \\
\hline Morphine consumption 24 hrs (mg), median (IQR) & $0(0,3)$ & $3(0,12)$ & $<0.001$ \\
\hline Durations of hospitalization (days), median (IQR) & $4(3,6)$ & $4(4,5)$ & 0.329 \\
\hline
\end{tabular}

Data are presented by number (\%), unless indicated otherwise

$\mathrm{RR}=$ recovery room, IQR=interquartile range, NSAIDs=non-steroidal anti-inflammatory drug, mcg=microgram, mg=milligram, IV=intravenous, hr=hour 
Table 3 Logistic regression analyses of factors associated with moderate to severe pain after laparoscopic surgery

\begin{tabular}{|c|c|c|c|c|}
\hline Factors & Crude OR $(95 \% \mathrm{Cl})$ & $p$-value & Adjusted OR (95\% CI) & p-value \\
\hline Age $\leq 40$ years & $0.88(0.49,1.57)$ & 0.657 & - & - \\
\hline $\mathrm{BMI} \geq 35 \mathrm{~kg} / \mathrm{m}^{2}$ & $2.33(1.12,4.84)$ & 0.023 & $1.97(0.9,4.31)$ & 0.085 \\
\hline Sex: Female & $1.09(0.61,1.95)$ & 0.768 & - & - \\
\hline ASA (Ref=class I) & & & & - \\
\hline Class II & $1.28(0.42,3.87)$ & 0.667 & - & \\
\hline Class III & $1.58(0.49,5.12)$ & 0.446 & - & \\
\hline \multicolumn{5}{|c|}{ Type of surgery (Ref=Bariatric surgery) } \\
\hline Gynecological & $0.33(0.13,0.83)$ & 0.018 & - & - \\
\hline Upper Gl surgery & $0.34(0.13,0.87)$ & 0.025 & - & \\
\hline Colorectal & $0.36(0.14,0.94)$ & 0.037 & - & \\
\hline Urological & $0.61(0.14,2.71)$ & 0.519 & - & \\
\hline Abdominal pressure $\geq 12 \mathrm{mmHg}$ & $1.84(0.8,4.22)$ & 0.153 & $2.83(1.03,7.77)$ & 0.04 \\
\hline Duration of surgery $>180$ mins & $1.49(0.86,2.61)$ & 0.158 & $2.23(1.12,4.42)$ & 0.02 \\
\hline Multiple ports & $1.15(0.4,3.31)$ & 0.789 & - & - \\
\hline Local infiltration & $1.42(0.55,3.68)$ & 0.472 & - & - \\
\hline \multicolumn{5}{|c|}{ Opioid intraoperative (Ref=Fentanyl) } \\
\hline Morphine & $0.19(0.04,0.82)$ & 0.026 & $0.16(0.04,0.71)$ & 0.033 \\
\hline Paracetamol IV intraoperative & $0.92(0.42,2.02)$ & 0.841 & - & - \\
\hline NSAIDs IV intraoperative & $0.81(0.43,1.53)$ & 0.517 & - & - \\
\hline
\end{tabular}

$\mathrm{OR}=\mathrm{odd}$ ratio, $\mathrm{Cl}=$ confidence interval, $\mathrm{BMl}=$ body mass index, $\mathrm{ASA}=\mathrm{American}$ Society of Anesthesiologists, $\mathrm{kg}=\mathrm{kilogram}, \mathrm{mm}=\mathrm{millimeter}$, $\mathrm{Hg}=$ mercury, min=minute, IV=intravenous, NSAIDs=non-steroidal anti-inflammatory drugs

\section{Discussion}

In this study, we found that approximately $50.0 \%$ of the patients suffered from moderate to severe pain after laparoscopic surgery. This result was consistently same as previous literature. ${ }^{3,4}$ Intra-abdominal pressure equal or more than $12 \mathrm{mmHg}$ and operation time more than 3 hours were significantly associated with moderate to severe pain whereas morphine as intraoperative analgesic drug significantly reduced the pain. There are several reasons for these associations.

On one hand, the intense pain in laparoscopic procedure could be determined as incisional pain and visceral pain from the effect of pneumoperitonuem. ${ }^{13}$ This retrospective study revealed that only abdominal pressure more than $12 \mathrm{mmHg}$ and duration of surgery more than 3 hours were associated with moderate to severe pain in laparoscopic procedure. This result was similar with previous literature ${ }^{8,13}$ Akkoc et al. reported that using low insufflation pressure $(10 \mathrm{mmHg})$ was associated with low postoperative pain score. ${ }^{13}$ Another study stated that postoperative pain score was significantly reduced in low abdominal pressure (8 $\mathrm{mmHg}$ ) compared with standard pressure $(12 \mathrm{mmHg}$ ) and high insufflation pressure $(15 \mathrm{mmHg}) .{ }^{14}$ According to the literature, correlation between high insufflation pressure and increased pain level is related to pneumoperitoneum effect. $\mathrm{CO}_{2}$ pneumoperitoneum causes peritoneal stretching, overdistension of diaphragmatic muscle fiber, stretching of nerve, and releasing of inflammatory response. ${ }^{15}$ This leads to visceral pain, and shoulder pain. However, low pressure of gas would limit surgical fields with eventual difficulty in operation, though we should confirm this result with a randomized control trial study.

Operation time is another factor which impacts moderate to severe pain. Prolonged operation time (more 
than 3 hours) in laparoscopic procedure increases risk of complications such as subcutaneous emphysema, and shoulder pain. ${ }^{16}$ This is the result of the prolongation of pneumoperitoneum effect.

In our study, we found that $\mathrm{BMI} \geq 35 \mathrm{~kg} / \mathrm{m}^{2}$ was not associated with pain. Several publications stated that obesity was not associated with postoperative pain. ${ }^{4,7,17}$ This was probably due to the pharmacokinetics of analgesia drugs. ${ }^{18}$ The metabolism of morphine was not altered in the morbidly obese when compared with normal volunteers. As a result, morphine-6-glucoronide (M6G) and morphine3-glucoronide (M3G), the metabolites of morphine, would effectively reduce pain equally between obese and nonobese. This assumes obesity would not be associated with postoperative pain.

Morphine and fentanyl are the most commonly used analgesic drugs worldwide. Their analgesia would be useful in intraoperative and postoperative period. Similarly, in this research, morphine had more potency than fentanyl in reducing postoperative pain. Previous research has revealed that fentanyl needs more effort to control pain due to fentanyl's lipophilic nature and its tendency to redistribute after administration in adipose tissues. The short duration of fentanyl effect is due to its rapid redistribution from sites of action in the brain to sites of storage (muscle and fat). ${ }^{19}$ These pharmacokinetic and pharmacodynamic properties were not seen in morphine. Morphine is primarily metabolized by the liver uridine diphosphate glucuronosyltransferase to active M3G and M6G. These contribute to the analgesic effect and they are eliminated by renal function (Creatinine clearance). ${ }^{20}$ resulting in the duration of morphine being longer than fentanyl. The limitation of this research is that it is a retrospective study with data analyzed from a single center. Additionally, there are a variety of laparoscopic surgeries that were included in this study for which the pain intensity would be different from each other.

\section{Conclusion}

Incidence of moderate to severe pain after laparoscopic surgeries is about $50.0 \%$. Intra-abdominal pressure $\geq 12 \mathrm{mmHg}$ and operation time more than 3 hours are the independent risk factors of postoperative moderate and severe pain in laparoscopic surgery. Furthermore, morphine should be the appropriate opioid used in intraoperative period for reducing probability of moderate to severe pain in the postoperative period, especially in patients requiring high abdominal pressure or complicated surgery that has long duration.

\section{Acknowledgements}

We would like to thank Associate Professor Paramee Thongsuksai and Epidermiology department for their contributions in study design.

\section{Conflict of interest}

There are no potential conflicts of interests to declare.

\section{References}

1. Gan TJ. Poorly controlled postoperative pain: prevalence, consequences, and prevention. Pain Res 2017;10:2287-98.

2. Ekstein P, Szold A, Sagie B, Werbin N, Klausner JM, Weinbroum AA. Laparoscopic surgery may be associated with severe pain and high analgesia requirements in the immediate postoperative period. Ann Surg 2006;243:41-6.

3. Adenekan AT, Aderounmu AA, Wuraola FO, Owojuyigbe AM, Adetoye AO, Nepogodiev D, et al. Feasibility study for a randomized clinical trial of bupivacaine, lidocaine with adrenaline, or placebo wound infiltration to reduce postoperative pain after laparoscopic cholecystectomy. BJS 2019;26:5.50159.

4. Silva LM da, Kakuda CM, Abib A de CV, Fugiwara FY, Lara GFL e, Mazzotta RC, et al. Fatores associados à dor pós-operatória na recuperação pós-anestésica em pacientes submetidos à gastroplastia laparoscópica. Rev Dor 2013;14: 239-44. 
5. Ip HYV, Abrishami A, Peng PWH, Wong J, Chung F. Predictors of postoperative pain and analgesic consumption: a qualitative systematic review. Anesthesiology 2009;111:657-77.

6. Zeidan A, Al-Temyatt S, Mowafi H, Ghattas T. Gender-related difference in postoperative pain after laparoscopic Roux-En-Y gastric bypass in morbidly obese patients. Obes Surg 2013; 23:1880-4.

7. Hartwig M, Allvin R, Bäckström R, Stenberg E. Factors associated with increased experience of postoperative pain after laparoscopic gastric bypass surgery. Obes Surg 2017; 27:1854-8.

8. Özdemir-van Brunschot DMD, van Laarhoven KCJHM, Scheffer GJ, Pouwels S, Wever KE, Warlé MC. What is the evidence for the use of low-pressure pneumoperitoneum? A systematic review. Surg Endosc 2016;30:2049-65.

9. Hsien CF, Wang CL, Long CY, Chen YH, Lee WYN, Chen $\mathrm{SC}$, et al. Factors associated with types and intensity of postoperative pain following gynecological laparoscopic surgery: a cross-sectional study. Biomed Res Int 2017;2017. doi:10.1155/2017/2470397.

10. Sugihara M, Miyake T, Miyagi $Y$, Oda $T$, Hazama $Y$, Sano R, et al. Does local infiltration anesthesia on laparoscopic surgical wounds reduce postoperative pain? Randomized control study. Reprod Med Biol 2018;17:474-80.

11. Kamali A, Ashrafi TH, Rakei S, Noori G, Norouzi A. A comparative study on the prophylactic effects of paracetamol and dexmedetomidine for controlling hemodynamics during surgery and postoperative pain in patients with laparoscopic cholecystectomy. Medicine (Baltimore) 2018;97. doi: 10.1097/ MD. 0000000000013330 .

12. Liu Y, Song X, Sun D, Wang J, Lan Y, Yang G, et al. Evaluation of intravenous parecoxib infusion pump of patient-controlled analgesia compared to fentanyl for postoperative pain management in laparoscopic liver resection. Med Sci Monit 2018;24:8224-31.
13. Akkoc A, Topaktas R, Aydin C, Altin S, Girgin R, Yagli OF, et al. Which intraperitoneal insufflation pressure should be used for less postoperative pain in transperitoneal laparoscopic urologic surgeries? Int Braz J Urol Off J Braz Soc Urol 2017;43:518-24.

14. Topçu HO, Cavkaytar S, Kokanalı K, Guzel Al, Islimye M, Doganay M. A prospective randomized trial of postoperative pain following different insufflation pressures during gynecologic laparoscopy. Eur J Obstet Gynecol Reprod Biol 2014;182: 81-5.

15. Choi JB, Kang K, Song MK, Seok S, Kim YH, Kim JE. Pain characteristics after total laparoscopic hysterectomy. Int $\mathrm{J}$ Med Sci 2016;13:562-8.

16. Atkinson TM, Giraud GD, Togioka BM, Jones DB, Cigarroa JE. Cardiovascular and ventilatory consequences of laparoscopic surgery. Circulation 2017;135:700-10.

17. Iamaroon A, Tangwiwat $S$, Nivatpumin $P$, Lertwacha $T$, Rungmongkolsab P, Pangthipampai P. Risk factors for moderate to severe pain during the first 24 hours after laparoscopic bariatric surgery while receiving intravenous patient-controlled analgesia. Anesthesiol Res Pract 2019. doi: 10.1155/2019/6593736.

18. de Hoogd S, Välitalo PAJ, Dahan A, van Kralingen S, Coughtrie MMW, van Dongen EPA, et al. Influence of morbid obesity on the pharmacokinetics of morphine, morphine-3-glucuronide, and morphine-6-glucuronide. Clin Pharmacokinet 2017;56: 1577-87.

19. Nada EM, Alabdulkareem A. Morphine versus fentanyl patientcontrolled analgesia for postoperative pain control in major hepatic resection surgeries including living liver donors: A retrospective study. Saudi J Anaesth 2018;12:250-5.

20. Anestez Z. A new goal in opioid management in obese patients: opioid free anesthesia. Anestezi Dergisi 2017;25:11721. 